\title{
Assessing clinical competency: The long and the short of it
}

Todd K. Rosengart, MD

Human performance deficiencies are responsible for slightly more than half of all adverse surgical outcomes, according to a review of approximately 5000 cases conducted by our Department of Surgery in 2018. ${ }^{1}$ Cognitive errors were found in this study to account for half of these human performance deficiencies. Extrapolated to the nearly 17 million operative procedures performed in the United States annually, these findings suggest that each year cognitive error is the source of nearly 200,000 potentially preventable surgical adverse events.

Multiple studies have documented the association of cognitive decline with aging, and the demonstrable deterioration of the cognitive and psychomotor function of physicians and surgeons beginning at least as early as age 60 years. ${ }^{2-4}$ In 2 different studies, surgeons aged 60 years or older demonstrated at least a 2 -fold increase in cognitive testing errors compared with younger surgeons. ${ }^{3,4}$ Surgeons aged 75 years and older have in turn been shown to exhibit declines in cognitive function as great as $25 \%$ of their baseline function.

Although it might be expected that these age-related declines in cognitive and psychomotor function would be closely associated with increasing surgical complication or mortality rates, such is not necessarily the case. For example, changes in cognitive function have been shown to vary increasingly with advancing age. ${ }^{5}$ Further, at least 2 studies have suggested that surgeon experience and/or a surgeon's self-selection of lower-risk cases can significantly mitigate the potentially increased complication risk associated with age-related deteriorations in surgeon performance. ${ }^{6,7}$ As a consequence of this acquired surgical wisdom, older surgeons were shown in these studies to often provide better outcomes than their younger counterparts, especially with higher-risk cases. These findings highlight experience-related gaps in cognitive and technical skills that may conversely challenge the performance of younger, less-experienced surgeons.

From the Michael E. DeBakey Department of Surgery, Baylor College of Medicine, Houston, Tex.

Presented at the 101st Annual Meeting of The American Association for Thoracic Surgery, Cardiothoracic Ethics Forum: Measuring Surgical Competence: Why, When, How, and What To Do About It, May 2, 2021.

Received for publication Sept 6, 2021; revisions received Oct 27, 2021; accepted for publication Nov 2, 2021; available ahead of print Nov 13, 2021.

Address for reprints: Todd K. Rosengart, MD, Department of Surgery, Baylor College of Medicine, One Baylor Plaza, MS 390, Houston, TX 77030 (E-mail: todd. rosengart@bcm.edu).

J Thorac Cardiovasc Surg 2022;164:1035-7

$0022-5223 / \$ 36.00$

Copyright (c) 2021 by The American Association for Thoracic Surgery

https://doi.org/10.1016/j.jtcvs.2021.11.022

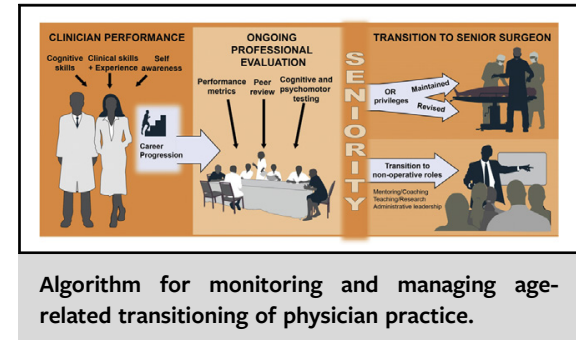

CENTRAL MESSAGE

Age-related cognitive decline is a potential risk factor for increased surgical complications. Cognitive and psychomotor testing of older physicians and surgeons is recommended to address this risk.

See Commentaries on pages 1038 and 1040.

Notwithstanding the mitigating elements of surgeon experience versus cognitive competency, as well as the confounding but potentially confounding contributions of the surgical team to the results and performance of a physically or cognitively declining surgeon, multiple studies have nevertheless demonstrated associations between advancing surgeon age and declining clinical performance. In 1 study of 8 procedure types that was adjusted for case risk and surgeon volume, higher mortality was seen for older versus younger surgeons (aged 60 years or older vs 40 years or younger) in 3 complex case types, including a $10 \%$ increase in operative mortality for coronary artery bypass surgery. ${ }^{7}$ As opposed to the selfaware case selection noted above, these findings may relate to the alarming observation that $30 \%$ of older surgeons did not perceive their own cognitive defects, and as many as $50 \%$ of deficient surgeons had no retirement plans that mitigate risk. ${ }^{4,8,9}$ Extrapolating these cognitive decline data to our human performance index, a $10 \%$ increase in agerelated adverse outcomes would translate to 20,000 added potentially avoidable adverse surgical events in the United States annually and as many as 1000 potentially avoidable US coronary bypass deaths annually - the proverbial jetliner crash almost every other month!

\section{LESSONS FROM THE AVIATION INDUSTRY}

Commercial aviation safety experts have told us that flying a jetliner is nowhere nearly as complicated as performing 
heart surgery (!). It is nevertheless instructive that pilot error has been reduced to a 6-sigma passenger mortality rate $<0.001 \%$, at least 1000 -fold better than that achieved for open heart surgery. This astounding gap has only widened since the 1999 publication of the Institute of Medicine's seminal report on avoidable mortality in health care. ${ }^{10}$

Although our profession has accordingly begun to adopt crew resource management and other safety strategies from the aviation industry, vast differences still exist between the safety cultures of our professions. Diligent monitoring of age-related deterioration in human performance, as manifested in the entry-level and ongoing certification of operators, is a prominent manifestation of this gap. For example, to become certified by the Federal Aviation Administration (FAA), pilots after achieving mandated flight hours must pass a (craft-specific) check-ride practical test with an FAA examiner evaluating in-air competencies, including routine and emergency maneuvers. Similar examinations of at least 1 hour's duration are required biannually. Even with ongoing certification, FAA-licensed pilot retirement is mandatory at age 65 years.

In comparison, physician certification requires serial resident case volume and competency reviews and successful completion of oral and/or written board exams before independent licensing; however, little to no practical skills demonstration is subsequently required by state licensing boards or hospital credentialing committees. Although current law allows hospitals to perform age-based competency evaluations, the 1967 federal Age Discrimination in Employment Act dissuades mandatory age-based retirement or even competency evaluation of senior physicians.

Instead of the skills-related practical exams mandated by the FAA for pilots, ongoing credentialing of physicians now largely occurs through open-book national board written exams and accrual of continuing medical education credits that are accepted by hospital review committees as a core component of their credentialing process. These re-privileging exercises are only loosely regulated by certifying bodies such as The Joint Commission, which mandates only ill-defined Ongoing Professional Performance Evaluations (OPPE) criteria to certify medical staff. Physician OPPE certifying metrics such as "periodic chart review," "appropriateness of test ordering," "code of conduct breaches," and "quality of documentation" are far removed from the technical skills observations and evaluations of performance judgment mandated for pilot recertification by the FAA.

\section{SOCIETY OF SURGICAL CHAIRS \\ RECOMMENDATIONS AND NEXT STEPS}

Given these gaps in physician competency certification standards, the Society of Surgical Chairs (SSC) in 2020 published recommendations on competency review and transitioning of senior surgeons. ${ }^{11}$ More than $85 \%$ of surgery chairs involved in this study noted this issue to be "significant" or "very significant" need. Although the SSC focused this effort on recommendations for senior surgeons, they noted similar competency considerations could well also apply to relatively inexperienced junior surgeons.

The SSC recommendations include cognitive and psychomotor testing beginning at least by age 65 years as a component of OPPE evaluations and restriction or modification of privileges as indicated by these evaluations (see Figure 1). The SSC guidelines also recommend transition planning beginning early career that include financial and

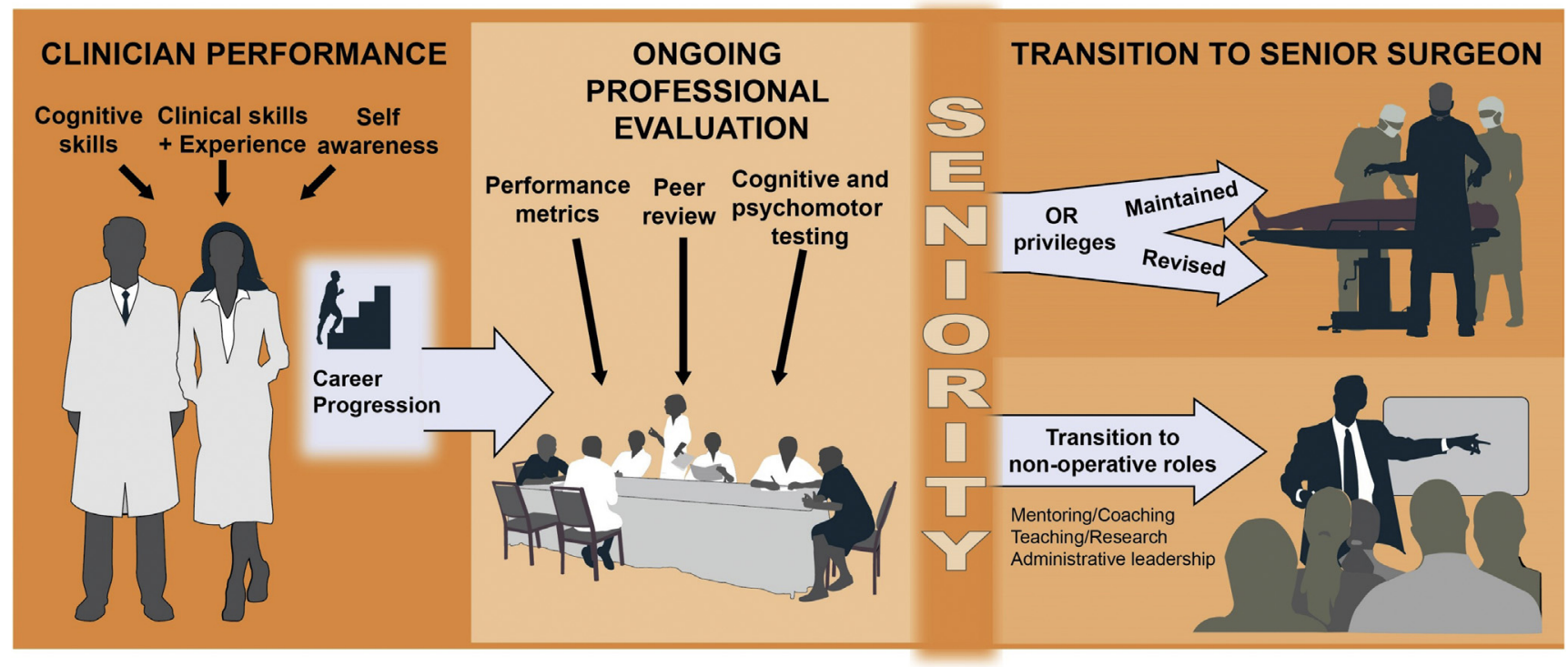

FIGURE 1. Schematic for transitioning senior surgeons, highlighting options for assessment and modification of professional roles and responsibilities. Reproduced with permission from reference 11. 
career option transition planning (eg, to teaching, mentoring, or administrative roles), mimicking the well-received opportunity given to FAA pilots to plan ahead in advance of known mandatory retirement requirements. Mentoring activities in particular could serve as an invaluable apprenticeship paradigm for junior surgeons but conversely provide a safety net of a younger, cognitive presence in the operating room.

In the context of the SSC guidelines, senior (and junior) surgeon competency could evaluated via unbiased, external reviews of STS outcomes data, operative videos, observations of proctored cases, or even simulation lab case scenarios assessing clinical knowledge and judgment skills. These evaluations could in turn be used by state or national boards and/or hospital credentialing committees that would likely not have the necessary assessment expertise to perform such evaluations or would be encumbered by potential conflicts of interest amongst peers.

If competency deficiencies were identified through these more robust OPPE processes, rectifying actions in addition to those already recommended by the SSC could include mandated so-called double-scrubbing or other practice modifications to match skills with privileges. Similar strategies could be applied in reverse to younger surgeons to match case complexity with case repetitions, technical fluency, and developing clinical skill sets.

It would be preferable for our profession to assume a leadership role in bringing our knowledge and experience to the effective enactment of such competency evaluation measures. These competency evaluation standards could be advanced by surgical leaders working with national boards and professional societies such as the American Association for Thoracic Surgery. These groups could in turn advocate such certification guidelines to state licensing and hospital boards as standards of care, much as practice guidelines are now integrated into our health care environment. The longer we abdicate our responsibility to enact such changes, the more likely less knowledgeable regulatory third parties will fill the void of our leadership on this issue, and potentially impose misdirected certification processes that could exclude capable practitioners from the care of patients in need.

\section{Conflict of Interest Statement}

The author reported no conflicts of interest.

The Journal policy requires editors and reviewers to disclose conflicts of interest and to decline handling or reviewing manuscripts for which they may have a conflict of interest. The editors and reviewers of this article have no conflicts of interest.

\section{References}

1. Suliburk JW, Buck QM, Pirko CJ, Massarweh NN, Barshes NR, Singh H, et al. Analysis of human performance deficiencies associated with surgical adverse events. JAMA Netw Open. 2019;2:e198067. https://doi.org/10.1001/jamanetworkopen.2019.8067

2. Powell DH, Whitla D. The Aging Intellect. Routledge; 2011.

3. Boom-Saad Z, Langenecker SA, Bieliauskas LA, Graver CJ, O'Neill JR, Caveney AF, et al. Surgeons outperform normative controls on neuropsychologic tests, but age-related decay of skills persist. Am J Surg. 2008;195:205-9.

4. Bieliauskas LA, Langenecker SA, Graver C, Lee HJ, O'Neill J, Greenfield LJ Cognitive changes and retirement among senior surgeons (CCRASS): results from the CCRASS study. J Am Coll Surg. 2008;207:69-78.

5. Powell DH, Whitla D. Profiles in Cognitive Aging. Harvard University Press: 1994.

6. Tsugawa Y, Jena Ab, Orav EJ, Blumenthal DM, Tsai TC, Mehtsun WT, et al. Age and sex of surgeons and mortality of older surgical patients: observational study. BMJ. 2018;361:k1343. https://doi.org/10.1136/bmj/k1343

7. Waljee JF, Greenfield LJ, Dimich JB, Birkmeyer JD. Surgeon age and operative mortality in the United States. Ann Surg. 2006;244:353-62.

8. Lee HJ, Drag LL, Bieliauskas LA, Langenecker SA, Graver C, O'Neill J, et al Results from the cognitive changes and retirement among senior surgeons selfreport survey. J Am Coll Surg. 2009;209:668-71.

9. Drag LL, Bieliauskas LA, Langenecker SA, Greendfield LJ. Cognitive functioning retirement status and age: results from the cognitive changes and retirement among senior surgeons self-report survey. J Am Coll Surg. 2010;211:303-7.

10. Institutes of Medicine. To Err is Human: Building a Safer Health System. National Academies Press; 1999.

11. Rosengart TK, Doherty G, Higgins R, Kibbe MR, Mosenthal AC. Transition planning for the senior surgeon: guidance and recommendations from the Society of Surgical Chairs. JAMA Surg. 2019;154:647-53.

Key Words: clinical competency, cognitive function, aging, transitioning 